\title{
Etnográfica
}

Revista do Centro em Rede de Investigação em

Antropologia

vol. 25 (3) | 2021

Vol. 25 (3)

\section{A loucura nos documentos brasileiros: da formação da cidadania e da conformação estatal}

Madness in Brazilian documents: the construction of citizenship and the state's conformation

\section{Lilian Leite Chaves}

\section{(2) OpenEdition}

\section{Journals}

Edição electrónica

URL: https://journals.openedition.org/etnografica/10682

DOI: $10.4000 /$ etnografica. 10682

ISSN: 2182-2891

\section{Editora}

Centro em Rede de Investigação em Antropologia

\section{Edição impressa}

Data de publição: 1 outubro 2021

Paginação: 633-655

ISSN: 0873-6561

\section{Refêrencia eletrónica}

Lilian Leite Chaves, «A loucura nos documentos brasileiros: da formação da cidadania e da conformação estatal», Etnográfica [Online], vol. 25 (3) | 2021, posto online no dia 29 outubro 2021 consultado o 09 janeiro 2022. URL: http://journals.openedition.org/etnografica/10682 ; DOI: https:// doi.org/10.4000/etnografica.10682

\section{(c) (7) \&}

Etnográfica is licensed under a Creative Commons Attribution-NonCommercial 4.0 International License. 


\section{A loucura nos documentos brasileiros: da formação da cidadania e da conformação estatal}

\section{Lilian Leite Chaves}

Este texto é um mapeamento de como a loucura aparece categorizada nos documentos burocráticos brasileiros em vigor de 1978, início da luta por reforma psiquiátrica, até a atualidade. Esse mapeamento se inspira nas proposições antropológicas acerca das capacidades criadoras dos documentos, das políticas públicas como constituintes do processo de conformação estatal e da administração e governança enquanto tecnologias de governo que criam segmentos específicos. O objetivo desse trabalho é mostrar que as mudanças de categorias oficializadas nos documentos estatais estão atreladas à reorientação da assistência em saúde mental, descortinando o imbricamento entre demandas de cidadania e de serviços. Faz parte desse objetivo, enfatizar a capacidade dos documentos de criarem realidades sociais a partir de intervenções administrativas e redefinição de limites (individuais, domésticos, profissionais, institucionais e estatais).

PALAVRAS-CHAVE: documentos, loucura, saúde mental, cidadania, Estado, política.

Madness in Brazilian documents: the construction of citizenship and the state's conformation - This text it's a mapping of how the madness appears categorized in the Brazilian bureaucratic documents in force of 1978, beginning of the fight for psychiatric reform, until the present time. This mapping is inspired by the anthropological propositions about the creative capacities of documents, the public policies as constituents of the process of state formation and about administration and governance while technologies of government that create specific segments. The objective of this study is to show that the changes in official categories in state documents are linked to the reorientation of mental health care, revealing the interrelationship between demands for citizenship and services. It is part of this objective to emphasize the capacity of the documents to create social realities as from administrative interventions and redefinition of boundaries (individual, domestic, professional, institutional and state).

KEYWORDS: documents, madness, mental health, citizenship, state, politics.

CHAVES, Lilian (lilianlchaves@gmail.com) - PPGANTS/UFRR, Brasil. 


\section{INTRODUÇÃO}

Psicopata, toxicômano, loucos de todo o gênero, loucura furiosa, doente mental, incapaz, irresponsável, inimputável, deficiente mental, portador de transtorno mental, usuários e pacientes são algumas das categorias presentes nos documentos burocráticos brasileiros que nos permitem seguir como a loucura vem sendo considerada pelo Estado tendo em vista as diretrizes que norteiam as leis e as políticas de governo. ${ }^{1}$ A mudança no uso das categorias sinaliza para alguns fatores e/ou acontecimentos que possibilitam tais classificações, dentre eles: a participação social na proposição e controle das políticas governamentais; a constituição de novos atores políticos, mudanças e acordos internacionais; a revisão e reestruturação do modelo assistencial; a busca pela cidadania e a defesa do estabelecimento de direitos específicos para "os loucos". ${ }^{2}$ Esses fatores entram em evidência no final da década de 1970, período da abertura pela redemocratização nacional e do início da organização da luta pela reforma psiquiátrica.

O objetivo deste artigo é mapear documentos burocráticos e resgatar categorias, considerando que a oficialização das categorias por esses documentos engendra individualidades e socialidades, trazendo implicações para a vida dos indivíduos e para as dinâmicas do Estado. Compõe esse objetivo o esforço de delinear como o reconhecimento do louco enquanto um indivíduo está atrelado às propostas de reestruturação da assistência em saúde mental e à noção de cidadania, e como a forma de definir e garantir direitos interfere e reorganiza as práticas estatais. De acordo com Peirano (2006a, 2006b), tanto a cidadania quanto o Estado precisam ser olhados como processos inacabados, pela ótica das formações sociais. Para a autora, os documentos transformam indivíduos em cidadãos e permitem executar uma arqueologia do Estado.

Para alcançar tais objetivos se efetuará a articulação de proposições antropológicas sobre documentos, políticas públicas e governança e administração. No âmbito das proposições antropológicas sobre documentos serão priorizadas

1 Este trabalho é um dos produtos resultantes do projeto "Levar a sério os pontos de vista dos loucos e as suas implicações nas discussões sobre a loucura na contemporaneidade brasileira" desenvolvido no âmbito do PNPD/Capes junto ao PPGAS/UFRN entre 2015 e 2019.

2 A categoria "louco" tem, em sua historicidade, camadas de sentidos que se depositaram com as disputas de saberes e de práticas de controle social em torno da loucura. Foucault (2007 [1972]) sinalizou que o louco, a partir do século XVIII, é facilmente apontado em contraposição à dificuldade de se explicar o que é loucura, pois esta escapa às tentativas de captura. Compreendendo que as categorias são esforços de saber e de poder, ambos com as suas dimensões repressoras e produtoras, como refletiu Foucault (2008 [1979]), o termo "louco" comporta as diversas tentativas de enquadramento da loucura, permitindo vislumbrar o que cada tentativa retém, o que deixa escapar, os limites e as realidades que criam para os saberes, as instituições e os sujeitos. No âmbito desse artigo, enfoca-se o termo louco enquanto um ponto de partida do qual derivam uma infinidade de classificações propostas tanto pelo senso comum quanto por saberes específicos e que são continuamente apropriadas e ressignificadas por áreas de conhecimento, instituições e sujeitos. 
as que se destinam a trabalhar com a dimensão criadora dos documentos, isto é, que olham os documentos como instrumentos de mudanças e propiciadores de realidades (Hull 2012; Pinto 2014; Lowenkron e Ferreira 2014; Vianna 2002, 2014; Maricato 2015). Quanto às proposições acerca das políticas públicas, se lançará mão daquelas que enfocam a capacidade da antropologia de se debruçar sobre o processo do "fazer-se Estado" (Lima e Castro 2015), do qual as políticas públicas tomam parte. As reflexões sobre administração e governança se configuram como um auxílio para a compreensão das tecnologias de governo (Teixeira e Lima 2010).

Essas reflexões se articulam pelo fato de os documentos serem simultaneamente linguagem estatal, instrumentos de operacionalização de políticas e dispositivos de poder. Assim, pode-se vislumbrar que a maneira como a loucura é considerada por essa linguagem liga-se diretamente à dinâmica de se criar segmentos sociais e serviços, bem como às proposições de políticas, contribuindo, consequentemente, com a sua parcela para o descortinamento do processo de conformação estatal.

Os documentos foram mapeados a partir de sites e plataformas governamentais considerando o período de 1978, ano em que se inicia a luta pela reforma psiquiátrica no Brasil, até a atualidade. Eles são oriundos de áreas que afetam e permeiam o campo da saúde mental, como saúde, assistência social, direito civil e penal, trabalho, habitação, etc. Fazem parte desse conjunto documentos internacionais elaborados por instâncias nas quais o Brasil participa ou que tenham influenciado diretamente o processo de reforma brasileiro, já que este se nutriu de reflexões e experiências internacionais acerca da loucura, sobretudo das que se pautavam por questionar o saber psiquiátrico com as suas violências físicas, psicológicas, assistenciais e morais.

O mapeamento, mesmo com o uso de ferramentas tecnológicas e recursos da web, se deu artesanalmente, pois não foi encontrada uma listagem completa e oficial de todos os documentos do campo da saúde mental e nem um instrumento que buscasse e organizasse esses documentos. Dessa maneira, mapear documentos é recolher pistas e construir narrativas, tendo em mente que o processo de busca esculpe o objeto de pesquisa, ponderação feita por Venâncio (2005) sobre estudos de arquivos. O mapeamento não é uma simples listagem, ele se configura como uma atividade de construção de memória seguindo um viés. Segundo Zeitlyn (2012), os arquivos em si não são uma memória, eles são disparadores de memórias que permitem novas narrativas sobre o passado, e também sobre o presente.

Para os fins desse artigo, serão considerados decretos, leis, projetos de lei, portarias, resoluções e relatórios finais de conferências; documentos que possibilitam apreender como os indivíduos vêm sendo classificados, como grupos de indivíduos são constantemente delimitados e como as diretrizes e normativas formam a cidadania e conformam o Estado. 


\section{A LOUCURA NOS DOCUMENTOS DA DÉCADA DE 1970 ATÉ A VIRADA DO MILÊNIO}

Em 1978, ainda estava em vigor a Lei n. 3071 de 1916/Código Civil, o Decreto-Lei n. ${ }^{\circ} 2848$ de 1940/Código Penal, o Decreto n. ${ }^{\circ} 60.252$ de 1967 que instituiu a Campanha Nacional de Saúde Mental, e o Decreto n. ${ }^{\circ} 66.623$ de 1970 que dispunha sobre a organização do Ministério da Saúde, estabelecendo a Divisão Nacional de Saúde Mental.

O Código Civil de 1916 alude à loucura na parte sobre as "Pessoas", na qual se definem as pessoas consideradas "absolutamente incapazes para exercer pessoalmente os atos da vida civil". ${ }^{3}$ Juntamente com os menores de 16 anos, os surdos-mudos que não podiam exprimir as suas vontades, e os ausentes, estavam os "loucos de todo o gênero". Por serem absolutamente incapazes, estabelecia-se a interdição para os loucos que deveria ser inscrita no registro público. A interdição é a via para se instituir a curatela e deveria ser promovida para o "louco de todo o gênero" por pai, mãe ou tutor. Ela poderia ser promovida ainda pelo Ministério Público para os casos de "loucura furiosa". Os "loucos de todo o gênero" não poderiam ser testemunhas e nem testamentarem. Além disso, estabelecia o recolhimento dos "loucos" em estabelecimentos adequados sempre que fosse "inconveniente conservá-los em casa" ou que fossem necessários tratamentos.

No Código Penal, ${ }^{4}$ considerando as alterações realizadas até 1978, a loucura aparece primeiramente na parte nomeada "Da responsabilidade", na seção "Irresponsáveis". São definidos como irresponsáveis os considerados isentos de pena, no caso, o agente que por “doença mental ou desenvolvimento mental incompleto ou retardado era, ao tempo da ação ou da omissão, inteiramente incapaz de entender o caráter criminoso do fato ou de determinar-se de acordo com esse entendimento". As principais penas previstas no Código Penal se referem à reclusão, detenção e multa. No âmbito da reclusão e detenção, “o sentenciado a que sobrevém doença mental deve ser recolhido a manicômio judiciário ou, à falta, a outro estabelecimento adequado, onde lhe seja assegurada a custódia, tempo de prisão preventiva ou provisória ou de internação em hospital”. Já em relação à multa: "É suspensa a execução da pena de multa, se sobrevém ao condenado doença mental".

O sujeito com doença mental é submetido às medidas de segurança que são aplicadas quando se verifica "a prática de fato previsto como crime e a periculosidade do agente". De forma circular, a "presunção por lei" de peri-

3 Brasil, 1916, Lei n. ${ }^{\circ} 3071$, de 1. ${ }^{\circ}$ de janeiro de 1916. Código Civil dos Estados Unidos do Brasil. Disponível em < http://www.planalto.gov.br/ccivil_03/leis/13071.htm > (última consulta em outubro de 2021).

4 Brasil, 1940, Decreto n. ${ }^{\circ}$ 2848, de 7 de dezembro de 1940. Código Penal. Disponível em < http:// www.planalto.gov.br/ccivil_03/decreto-lei/del2848.htm > (última consulta em outubro de 2021). 
culosidade recai automaticamente sobre o agente que por doença mental ou desenvolvimento mental incompleto ou retardado não entende o caráter criminoso do fato. Tanto na parte dos irresponsáveis quanto na parte da presunção de periculosidade encontram-se também as pessoas em estado de embriaguez completa e habitual pelo álcool e substâncias de efeitos análogos, os ébrios habituais e os toxicômanos.

As medidas de segurança, para todos os casos, duram enquanto se verifica a periculosidade, podendo ser detentiva (internação em manicômio judiciário, internação em casa de custódia e tratamento, internação em colônia agrícola ou em instituto de trabalho, de reeducação ou de ensino profissional) ou não detentiva (liberdade vigiada, proibição de frequentar determinados lugares, exílio local). Para as colônias agrícolas eram destinadas, dentre outras pessoas, aquelas cujos crimes estavam relacionados com a ociosidade, a vadiagem e a prostituição. Já a liberdade vigiada poderia recair sobre os egressos de casa de custódia e tratamento e das colônias.

O Decreto n. ${ }^{\circ}$ 60.252, de 21 de fevereiro de 1967, institui, ${ }^{5}$ no Ministério da Saúde, a Campanha Nacional de Saúde Mental destinada à assistência, ao tratamento e reabilitação de psicopatas com hospitalização e atendimento ambulatorial ou de outra natureza; à promoção e realização de atividade de psiquiatria preventiva, através de campanhas de higiene mental e de combate aos fatores que afetam a saúde psíquica dos povos; e medidas destinadas à prevenção, combate, tratamento e recuperação do alcoolismo, da dependência e da toxicomania. Já o Decreto n. ${ }^{\circ}$ 66.623, de 22 de maio de $1970,{ }^{6}$ ao dispor sobre a organização do Ministério da Saúde, estabelece a Divisão Nacional de Saúde Mental/Dinsam, com o objetivo de "planejar, coordenar, fiscalizar os serviços de assistência e reabilitação de psicopatas assim como os serviços de higiene mental; assistir supletivamente a outros órgãos públicos e entidades privadas na prestação de serviços de proteção e recuperação da saúde mental".

As categorias presentes nestes documentos - psicopatas, loucos de todo o gênero, loucos furiosos, absolutamente incapazes, irresponsáveis, doentes mentais, ébrios habituais e toxicômanos - são reflexos do casamento entre o Direito e a Medicina que marca a história da loucura na passagem do século XIX para o XX. No Brasil, segundo Russo (1993), esse casamento se deu inicialmente com a constituição da Medicina Legal, considerando o interesse nas questões sobre a responsabilidade, a liberdade e a tutela do indivíduo louco. A vertente higienista, perceptível nesses documentos, é analisada por Costa (2007) como um

5 Brasil, 1967, Decreto n. ${ }^{\circ}$ 60.252, de 21 de fevereiro de 1967. Disponível em < https://www2. camara.leg.br/legin/fed/decret/1960-1969/decreto-60252-21-fevereiro-1967-401028-publicacaoorigin al-1-pe.html > (última consulta em outubro de 2021).

6 Brasil, 1970, Decreto n. ${ }^{\circ}$ 66.623, de 22 de maio de 1970. Disponível em < https://www2.camara. leg.br/legin/fed/decret/1970-1979/decreto-66623-22-maio-1970-408086-norma-pe.html > (última consulta em outubro 2021). 
movimento atrelado a higiene pública pela construção de hospícios para que os loucos, transformados em doentes mentais, pudessem ter assistência médica específica. Essas categorias podem ser vistas como pertencentes às fases de legitimação científica e de introdução da psiquiatria social, fases propostas por Medeiros (1993) para organizar a história da psiquiatria brasileira.

No ano de 1978 ocorre uma série de denúncias sobre o funcionamento desses serviços destinados aos doentes mentais, denúncias acerca da precarização do trabalho dos técnicos em saúde, de violências e maus-tratos. Amarante (2009) contextualiza que o início da Reforma Psiquiátrica brasileira se dá com a mobilização dos trabalhadores das unidades do Rio de Janeiro pertencentes à Divisão Nacional de Saúde Mental/Dinsam - Centro Psiquiátrico Pedro II, Hospital Pinel, Colônia Juliano Moreira e Manicômio Judiciário Heitor Carrilho. Essa mobilização ganhou projeção nacional na medida em que denunciava situações que se repetiam em outros cantos do país.

A publicação da Lei n. ${ }^{\circ}$ 180, em 1978 na Itália, ${ }^{7}$ conhecida como a Lei Basaglia, influenciou os rumos que o movimento brasileiro pela reforma psiquiátrica tomaria na década de 1980. Esta lei regulava sobre controles e tratamentos sanitários obrigatórios e voluntários, proibia a construção de novos hospitais psiquiátricos e a transformação de seções hospitalares já existentes em divisões psiquiátricas, controlava as internações psiquiátricas e defendia os serviços extra-hospitalares, considerando a dignidade da pessoa, os direitos civis e políticos garantidos pela Constituição. Dentre os direitos expostos nessa lei estão: o direito à escolha do médico e do local de tratamento, à comunicação do paciente com quem julgar importante durante o decurso do tratamento, à atenção extra-hospitalar e o de ter a sua internação comunicada à justiça e administração, que se tornam corresponsáveis pelo processo. A Lei n. ${ }^{\circ} 180$ ordenou a supressão das expressões "alienados de mente" e "enfermos de mente" do Código Penal italiano. A categoria usada na lei é de "doentes mentais" e seu objetivo é operar a desinstitucionalização.

A desinstitucionalização, inerente à lei italiana, ecoou no Brasil e teve impacto no Código Penal, que sofreu uma alteração no ano de 1984, referente à inimputabilidade e à medida de segurança. A seção nomeada de "Irresponsáveis" passou a se chamar "Inimputáveis", e a medida de segurança, além do caráter detentivo, passou a contar com a modalidade restritiva na qual o agente deveria comparecer ao ambulatório para tratamento nos dias estipulados pelos médicos. A exposição de motivos $211,{ }^{8}$ que explica as alterações no

7 Itália, 1978, Lei n. ${ }^{\circ}$ 180, de 13 de maio de 1978. Disponível em < http://laps.ensp.fiocruz.br/ arquivos/documentos/21 > (última consulta em outubro de 2021).

8 Brasil, 1983, Exposição de Motivo 211 , de 9 maio de 1983. Disponível em < https://www2. camara.leg.br/legin/fed/declei/1940-1949/decreto-lei-2848-7-dezembro-1940-412868-exposicaodemot ivos-148972-pe.html > (última consulta em outubro de 2021). 
Código Penal previstas pela Lei n. $^{\circ} 7209$, considera a medida de segurança restritiva como uma inovação que corresponde "às atuais tendências de 'desinstitucionalização", sem o exagero de eliminar a internação".

O relatório final da I Conferência Nacional de Saúde Mental (I CNSM), realizada em junho de 1987, também demonstra como a lei italiana foi lida no Brasil e dá o tom para uma mudança na concepção de pessoas e serviços. A I CNSM é um desdobramento da 8. ${ }^{a}$ Conferência Nacional de Saúde, marco da reforma sanitária brasileira para a criação do Sistema Único de Saúde (SUS), e tem como um dos objetivos "a inserção das ações de saúde mental nas ações de saúde em geral" (Ministério da Saúde 1988: 9). Pactuou-se nessa conferência pelo estabelecimento de direitos, deveres e legislação específicos para "o doente mental". Dessa maneira, enfatiza-se a discussão a respeito da cidadania e demanda-se que seja "constitucionalmente assegurada a condição de cidadania plena ao indivíduo considerado doente mental" (Ministério da Saúde 1988: 21).

Nessa conferência, se estipulou como norte a busca por uma assistência extra-hospitalar e multiprofissional, revertendo a tendência "hospitalocêntrica e psiquiatrocêntrica" e propiciando "uma visão integral do sujeito usuário do setor". Pactuou-se pela não construção de novos hospitais psiquiátricos, pela redução de leitos nos hospitais psiquiátricos existentes, pela substituição dos leitos psiquiátricos por serviços alternativos à internação hospitalar. As demandas por cidadania e mudanças na atenção traziam em seus bojos a defesa dos espaços de participação social para tomada de decisões referentes às políticas públicas; críticas sobre as estruturas dos manicômios judiciários, as interdições dos loucos de todo o gênero, as noções de incapacidade, inimputabilidade e periculosidade; e o apontamento da dimensão produtiva e laboral tanto no desencadeamento de distúrbios mentais, quanto na reinserção social, através do trabalho protegido, das pessoas segregadas devido aos diagnósticos psiquiátricos.

O que se pactuou na I CNSM é fruto de uma tentativa nacional de enfrentamento do problema da assistência psiquiátrica e do tratamento dos indivíduos considerados loucos. Essa conferência marca o esforço de se construir um campo de atuação e novos sujeitos. Em suas diretrizes, não há mais espaço para psicopatas, loucos furiosos ou de todo o gênero, e sim para pessoas doentes mentais que têm direito à doença e direito à saúde, na qualidade de usuários. As suas diretrizes sugerem enquadramentos para a Constituição Federal de 1988, para as leis ordinárias como os Códigos Civil e Penal; fundamentam as discussões que culminam no Projeto de Lei n. 3657 de 1989; e preparam o terreno para as experimentações e acordos na década de 1990.

A loucura na Constituição Federal de 1988 está subsumida na ampla categoria de "deficiência" que aparece no item da "Assistência Social" e para a qual se objetiva a habilitação e reabilitação, a promoção da integração à vida 
comunitária, e a garantia de um salário mínimo de benefício mensal a pessoa que comprove a inexistência de meios para prover à própria manutenção ou de tê-la provida por sua família (Brasil 2007 [1988]). O Projeto de Lei n. ${ }^{\circ} 3657$ de 1989, proposto pelo então deputado Paulo Delgado, abre as discussões sobre a reforma psiquiátrica no legislativo, propondo a extinção dos manicômios, a substituição por outros recursos assistenciais e a regulamentação da internação compulsória (Delgado 1989). No corpo do projeto há a referência a "usuários" e "cidadão internado", categorias que substituem a de louco e englobam a de doente mental.

Na década de 1990, enquanto se discutia nas casas legislativas o teor do Projeto de Lei n. ${ }^{\circ}$ 3657, algumas experiências foram levadas a cabo ancorando-se nos princípios da Lei n. ${ }^{\circ} 8080$ de 1990 e da Resolução da ONU n. ${ }^{\circ}$ 46/1 19 de 1991. A Lei n. ${ }^{\circ} 8080,{ }^{9}$ lei orgânica de saúde, trouxe o conceito de saúde ampliado, para o qual "os níveis de saúde expressam a organização social e econômica do País" e as ações de saúde se destinam "a garantir às pessoas e à coletividade condições de bem-estar físico, mental e social". Por sua vez, a Resolução da ONU n. ${ }^{\circ}$ 46/119 de 1991 estipulou os princípios para a proteção das pessoas com doenças mentais e para a melhoria assistência em saúde mental. ${ }^{10}$ Essa resolução, ao ressaltar a atenção comunitária e a garantia dos direitos do doente mental, esmiúça a importância do trabalho, da renda, do acesso à informação, da lisura no diagnóstico, de se proibir a medicação não justificada e a esterilização, do consentimento do paciente ao tratamento, da não discriminação, do sigilo das informações que dizem respeito ao paciente, do direito à representação e de apresentar queixas, etc. As categorias prevalecentes nesse documento são pacientes e pessoas com doença mental.

Nessa década, os serviços de saúde mental comunitários foram regulamentados na rede do SUS pela Portaria SAS/MS n. ${ }^{\circ} 224$ de 1992 que, segundo Tenório (2002), divide o atendimento em saúde mental em hospitalar e ambulatorial; ${ }^{11}$ ocorreu a II Conferência Nacional de Saúde em 1992; se estipulou o Benefício da Prestação Continuada pela Lei Orgânica de Assistência Social/Lei n. ${ }^{\circ} 8742$ de $1993 ;{ }^{12}$ foi regulamentada a política nacional para a integração da pessoa

9 Brasil, 1990, Lei n. ${ }^{\circ} 8080$ de 19 de setembro de 1990. Disponível em < http://www.planalto.gov. br/ccivil_03/leis/18080.htm > (última consulta em outubro de 2021).

10 United Nations General Assembly, 1991, "Principles for the protection of persons with mental illness and the improvement of mental health care". Disponível em $<$ https:/www.who.int/mental_ health/policy/en/UN_Resolution_on_protection_of_persons_with_mental_illness.pdf. > (última consulta em outubro de 2021).

11 Brasil, 1992, Portaria SAS/MS n. 224 de 29 de janeiro de 1992. Disponível em < https://www. saude.mg.gov.br/index.php? option $=$ com_gmg\&controller $=$ document $\& i d=836$ - portaria-sas-ms-n \%C2\%BA-224-de-29-01-1992-se smg\&task=download > (última consulta em outubro de 2021).

12 Brasil, 1993, Lei n. ${ }^{\circ} 8742$ de 7 de dezembro de 1993. Disponível em < http://www.planalto.gov. br/ccivil_03/leis/18742.htm > (última consulta em outubro de 2021). 
portadora de deficiência, pelo Decreto n. ${ }^{\circ} 3298$ de $1999 ; ;^{13}$ e criaram-se as cooperativas sociais para pessoas em desvantagem social, com a Lei n. ${ }^{\circ} 9867$ de 1999. ${ }^{14}$ Desses documentos destacam-se as categorias: "doente mental", "pessoas com transtorno mental", "pessoas com sofrimento psíquico", "usuários" (usadas no âmbito da saúde), "deficiente" (assistência social), "deficiente mental” (direitos individuais e sociais), "deficientes psíquicos e mentais, pessoas dependentes de acompanhamento psiquiátrico permanente, e os egressos de hospitais psiquiátricos" (economia e trabalho).

Percebe-se que há um aumento das categorias usadas, e isso se dá devido às considerações de outras áreas profissionais e assistenciais. O relatório final da II CNSM estabelece a necessidade de "mudança no modo de pensar a pessoa com transtornos mentais em sua existência-sofrimento, e não apenas a partir de seu diagnóstico" e de "diversificação das referências conceituais e operacionais, indo além das fronteiras delimitadas pelas profissões clássicas em saúde mental" (Ministério da Saúde 1992: 6). A diversificação das referências conceituais e operacionais é consonante com os novos contornos que a saúde, a assistência social, o trabalho e a renda ganham depois da Constituição de 1988, quando são desprendidos do campo da Previdência Social e inseridos no campo da Seguridade Social.

Com essa amplitude, é possível apontar que nos documentos de saúde prevalecem as categorias de usuário, pacientes, e as que indicam sofrimento, doença e transtorno. Já nos documentos de outras áreas, sobretudo das áreas referentes aos benefícios sociais, trabalho e renda, prevalece a categoria deficiente, que ora aparece sozinha de maneira generalizante, ora aparece composta com o qualificativo mental e/ou psíquico, e ora vem adicionada com as noções de pessoas dependentes de acompanhamento psiquiátrico permanente e egressos de hospitais psiquiátricos. O uso da noção de deficiência e da categoria deficiente pode ser mais bem compreendido se consideramos que estava presente no relatório da II CNSM a demanda para "assegurar ao portador de transtorno ou deficiência mental os mesmos benefícios concedidos e garantidos, pela Constituição de 1988, aos deficientes físicos" (Ministério da Saúde 1992: 23).

\section{LOUCURA NOS DOCUMENTOS DO NOVO MILÊNIO}

O Projeto de Lei n. ${ }^{\circ}$ 3657, que enfocava a extinção dos manicômios, depois de mais de uma década de discussão, culmina na Lei n. ${ }^{\circ} 10.216$ de $2001,{ }^{15}$

13 Brasil, 1999, Decreto n. 3298 de 20 de dezembro de 1999. Disponível em < http://www.planalto. gov.br/ccivil_03/decreto/d3298.htm > (última consulta em outubro de 2021).

14 Brasil, 1999, Lei n. 9867 de 10 de novembro de 1999. Disponível em < http://www.planalto.gov. br/ccivil_03/Leis/L9867.htm > (última consulta em outubro de 2021).

15 Brasil, 2001, Lei n. ${ }^{\circ} 10.216$ de 6 de abril de 2001. Disponível em < http://www.planalto.gov.br/ ccivil_03/leis/leis_2001/110216.htm > (última consulta em outubro de 2021). 
que enfatiza "a proteção e os direitos das pessoas portadoras de transtornos mentais e redireciona o modelo assistencial em saúde mental”. Nessa lei, que orienta a política nacional de saúde mental até a atualidade, estão presentes as categorias pacientes e pessoas portadoras de transtorno mental. Dentre os direitos garantidos a essas pessoas, destacam-se: ser tratada com humanidade e respeito, ser protegida contra qualquer forma de abuso e exploração; ter garantia de sigilo nas informações prestadas; ter acesso à informação a respeito da sua doença e de seu tratamento; ter livre acesso aos meios de comunicação; ser tratada em ambiente terapêutico pelos meios menos invasivos possíveis, preferencialmente em serviços comunitários.

A primeira década dos anos 2000 conta com a III Conferência Nacional de Saúde Mental, com a entrada em vigor da Lei n. ${ }^{\circ} 10.406$ de 2002, que institui um novo Código Civil, e com normativas que operacionalizam o redirecionamento do modelo assistencial, como exemplos, a Portaria GM/MS n. ${ }^{\circ} 336$ de 2002, a portaria GM/MS n. ${ }^{\circ} 816$ de 2002 e a resolução CNPCP n. ${ }^{\circ} 05$ de 2004.

No relatório da III CNSM (SUS 2002) não consta o uso da categoria doente mental, figurando as categorias "portador de transtorno mental", "portador de sofrimento mental" e "portador de sofrimento psíquico". Em suas diretrizes, há a consideração dos dependentes químicos como sujeitos que devem ser enquadrados nas ações de saúde mental. Neste âmbito, esta conferência reafirma que as dependências do álcool e outras drogas são questões de saúde pública que precisam de atenção específica, ideia que está presente nas políticas brasileiras desde a instituição da Campanha Nacional de Saúde Mental em 1967. A Portaria GM/MS n. ${ }^{\circ} 336,{ }^{16}$ e a Portaria GM/MS n. ${ }^{\circ} 816,{ }^{17}$ ambas de 2002, merecem destaque porque garantiram dispositivos comunitários e ações específicas em saúde mental, incluindo os usuários de álcool e outras drogas, e reafirmando a atenção a esses usuários enquanto competência da saúde mental. A Portaria GM/MS n. ${ }^{\circ} 336$ estabeleceu os Centros de Atenção Psicossocial, dentre eles o Centro de Atenção Psicossocial Álcool e Drogas/CAPS AD, e a Portaria GM/MS n. ${ }^{\circ} 816$ instituiu o Programa Nacional de Atenção Comunitária Integrada a Usuários de Álcool e Outras Drogas.

Outra diretriz da III CNSM é relativa à supressão, no Código Civil, da categoria "loucos de todo o gênero" e da consideração destes como absolutamente incapazes. Esta diretriz acompanha a demanda de uma legislação que reconheça o portador de transtornos mentais como um sujeito de direitos, que revise os critérios da interdição propondo uma curatela parcial constantemente reavaliada e com mais possibilidades de reversão. Aliada a discussão sobre o

16 Brasil, 2002, Portaria GM/MS n. ${ }^{\circ} 336$ de 19 de fevereiro de 2002. Disponível em < http://bvsms. saude.gov.br/bvs/saudelegis/gm/2002/prt0336_19_02_2002.html > (última consulta em outubro de $2021)$.

17 Brasil, 2002, Portaria GM/MS n. ${ }^{\circ} 816$ de 30 de abril de 2002. Disponível em < http://bvsms.saude. gov.br/bvs/saudelegis/gm/2002/prt0816_30_04_2002.html > (última consulta em outubro de 2021). 
Código Civil, exigiu-se a exclusão, no Código Penal, da "presunção de periculosidade" do portador de transtorno mental infrator, garantindo a ele o direito à responsabilidade e extinguindo a reclusão em hospitais de custódia e tratamento psiquiátrico.

Em 2002, foi aprovado um novo Código Civil, Lei n. ${ }^{0} 10.406,{ }^{18}$ que contemplou em partes o que foi pactuado na III CNSM. Se seguirmos o quadro comparativo entre o Código Civil de 1916 e o de 2002, elaborado pelo Senado Federal (Brasil 2003), percebemos, na parte que trata das pessoas absolutamente incapazes de exercerem os atos da vida civil, que a categoria "loucos de todo o gênero" foi substituída por "os que, por enfermidade ou deficiência mental, não tiverem o necessário discernimento para a prática desses atos". A mudança na categoria não proporcionou nenhuma alteração relativa à interdição civil e à curatela, mas se constituiu um avanço se considerarmos, como elencou Delgado (1992), que essa noção se fazia presente desde o Código Civil do Império e que englobava um elenco extenso e não específico de indivíduos sobre os quais o Estado estenderia seu manto tutelar.

No que tange ao Código Penal, as propostas da III CNSM subsidiaram a Resolução n. ${ }^{\circ} 05$ do Conselho Nacional de Política Criminal do Ministério da Justiça. ${ }^{19}$ Esta resolução aprovou como propostas um programa individualizado de tratamento com equipe multidisciplinar para cada paciente; a necessidade de políticas intersetoriais para os pacientes inimputáveis; a integração dos Hospitais de Custódia e Tratamento à rede SUS, regulamentando as internações e fazendo com que a aplicação da medida de segurança ocorra "de forma progressiva por meio de saídas terapêuticas, evoluindo para regime de hospital-dia ou hospital-noite e outros serviços de atenção diária".

Nessa década, verifica-se ainda a entrada em vigor de decretos, leis e portarias e a publicação de relatórios que demonstram a articulação do campo da saúde mental com outros setores, isto é, a dimensão intersetorial que se abre quando se considera cada vez mais a pessoa portadora de transtornos mentais como um sujeito integral e de direitos. A título de exemplo, é possível salientar, por um lado, a intersetorialidade com esferas mais "clássicas" como a Assistência Social, a Justiça e o Ministério do Trabalho; por outro, a intersetorialidade com a Secretaria dos Direitos Humanos, o Ministério da Cultura e o Ministério da Educação. Além desses documentos, é importante ressaltar que nessa década o Brasil aprova, ratifica e promulga o texto da Convenção Internacional sobre os Direitos das Pessoas com Deficiência e seu Protocolo Facultativo.

18 Brasil, 2002, Lei n. ${ }^{\circ} 10.406$ de 10 de janeiro de 2002. Código Civil. Disponível em < http://www. planalto.gov.br/ccivil_03/leis/2002/L10406compilada.htm > (última consulta em outubro de 2021).

19 Conselho Nacional de Política Criminal e Penitenciária, 2004, Resolução CNCPC n ${ }^{0} 05$ de 4 de maio de 2004. Disponível em < https://www.gov.br/depen/pt-br/composicao/cnpcp/resolucoes/2004/ resolucaono05de04demaiode2004.pdf.> (última consulta em outubro de 2021). 
Para o primeiro conjunto, percebe-se a intersetorialidade com a Assistência Social por meio da Lei n. ${ }^{\circ} 10.708$ de $2003,{ }^{20}$ que "institui o auxílio-reabilitação psicossocial para pacientes acometidos de transtornos mentais egressos de internações", auxílio que fundamenta o Programa de Volta para Casa; com a Justiça através da Portaria Interministerial MJ/MS n. ${ }^{\circ} 1777$ de $2003,{ }^{21}$ que "aprova o plano nacional de saúde no sistema penitenciário" e da Lei n. ${ }^{\circ} 11.343$ de $2006,{ }^{22}$ que "institui o Sistema Nacional de Políticas Públicas sobre Drogas - Sisnad" prescrevendo dentre outras medidas a atenção e reinserção social de usuários e dependentes de drogas; com o Ministério do Trabalho mediante a Portaria Interministerial MTE/MS n. 353 de $2005,{ }^{23}$ que "institui o Grupo de Trabalho de Saúde Mental e Economia Solidária" a fim de "propor e estabelecer mecanismos de articulação entre as ações das políticas de saúde mental e economia solidária".

Para o segundo conjunto, destaca-se a intersetorialidade com os Direitos Humanos a partir da Portaria Interministerial n. 3347 de 2006, ${ }^{24}$ que "institui o Núcleo Brasileiro de Direitos Humanos e Saúde Mental"; com o Ministério da Cultura através do "Relatório final da Oficina Nacional de Indicação de Políticas Públicas Culturais para Pessoas em Sofrimento Mental e em Situações de Risco Social" de 2007, que culminou no prêmio "Loucos pela Diversidade" ${ }^{25}$ destinado a premiar iniciativas culturais de instituições públicas, privadas, ou organizações da sociedade civil sem fins lucrativos, grupos artísticos ou artistas sem vínculo institucional que atuam na interface entre saúde mental e cultura, e pessoas em sofrimento psíquico; com o Ministério da Educação apoiada no Decreto n. ${ }^{\circ} 6286$ de $2007,{ }^{26}$ que "institui o programa saúde na escola" e tem como um dos objetivos "fortalecer o enfrentamento das vulnerabilidades no campo da saúde, que possam comprometer o pleno desenvolvimento escolar" e como ação prevista "a avaliação psicossocial".

20 Brasil, 2003, Lei n. ${ }^{\circ} 10.708$ de 31 de julho de 2003. Disponível em < http://www.planalto.gov.br/ ccivil_03/leis/2003/110.708.htm > (última consulta em outubro de 2021).

21 Brasil, 2003, Portaria Interministerial MJ/MS n. ${ }^{\circ} 1777$ de 09 de setembro de 2003. Disponível em $<$ https://www.legisweb.com.br/legislacao/?id=184949 > (última consulta em outubro de 2021).

22 Brasil, 2006, Lei n. ${ }^{o} 11.343$ de 23 de agosto de 2006. Disponível em < http://www.planalto.gov. br/ccivil_03/_ato2004-2006/2006/lei/11 1343.htm > (última consulta em outubro de 2021).

23 Brasil, 2005, Portaria Interministerial MTE/MS no 353, de 07 de março de 2005. Disponível em $<$ https://www.normasbrasil.com.br/norma/portaria-interministerial-353-2005_192072.html > (última consulta em outubro de 2021).

24 Brasil, 2006, Portaria Interministerial $\mathrm{n}^{\circ}$ 3347, de 29 de dezembro de 2006. Disponível em $<$ https://www.legisweb.com.br/legislacao/?id=199256 > (última consulta em outubro de 2021).

25 Ministério da Cultura, 2007, "Edital Prêmio Loucos pela Diversidade". Brasília: Secretaria da Identidade e Diversidade Cultural. Disponível em < http://rubi.casaruibarbosa.gov.br/handle/20.50 $0.11997 / 7127>$ (última consulta em outubro de 2021).

26 Brasil, 2007, Decreto n. ${ }^{\circ}$ 6286, de 5 de dezembro de 2007. Disponível em < http://www.planalto. gov.br/ccivil_03/_ato2007-2010/2007/decreto/d6286.htm > (última consulta em outubro de 2021). 
Com o Decreto Legislativo n. ${ }^{\circ} 186$ de $2008,{ }^{27}$ e com o Decreto n. ${ }^{\circ} 6949$ de $2009,{ }^{28}$ o Brasil aprova e promulga, respectivamente, a Convenção Internacional sobre os Direitos das Pessoas com Deficiência, cujo objetivo maior é "promover, proteger e assegurar o exercício pleno e equitativo de todos os direitos humanos e liberdades fundamentais por todas as pessoas com deficiência e promover o respeito pela sua dignidade inerente". A definição de pessoas com deficiência recai sobre "aquelas que têm impedimentos de longo prazo de natureza física, mental, intelectual ou sensorial, os quais, em interação com diversas barreiras, podem obstruir sua participação plena e efetiva na sociedade em igualdade de condições com as demais pessoas". Essa definição é muito importante porque a categoria "deficiência" é cara para as pessoas portadoras de transtornos mentais, uma vez que é através dela que estas pessoas são enquadradas em ações da assistência social, do trabalho e da geração de renda, permitindo o acesso a benefícios, isenções e participação em cooperativas sociais.

A década atual é marcada, em sua maior parte, pela consolidação das ações intersetoriais e da Rede de Atenção Psicossocial, e pela promulgação do Estatuto da Pessoa com Deficiência, que causa impactos importantes no Código Civil. Em contrapartida, de 2015 em diante, se acentuam as disputas políticas quanto ao modelo de assistência que vem sendo experimentado e consolidado desde a década de 1990 (Chaves 2016). Essas disputas, devido à alteração de gestores, geraram mudanças na Política Nacional de Saúde Mental no ano de 2017, concernentes às ações relativas aos usuários de álcool e outras drogas e aos tratamentos psiquiátricos. Por essas mudanças serem ainda recentes e se inserirem em grande parte na rubrica dos financiamentos e custeio, os documentos referentes a elas ultrapassam os limites desse artigo.

O relatório final da IV Conferência Nacional de Saúde Mental - Intersetorial abre o conjunto de documentos do período de 2010 a 2018. A palavra "intersetorial", integrante do título desta conferência, demonstra uma novidade e um avanço na maneira de se discutir as políticas de saúde mental, pois contou com a presença de representantes de outras políticas. Conceber uma conferência intersetorial evidencia que o campo da saúde mental "se insere no campo da saúde e ao mesmo tempo o transcende, com interfaces importantes e necessárias reciprocamente entre ele e os campos dos direitos humanos, assistência social, educação, justiça, trabalho e economia solidária, habitação, cultura, lazer e esportes, etc." (SUS 2010: 09). O relatório da IV CNSM organiza as diretrizes pactuadas em três eixos: políticas sociais e de Estado; rede de atenção

27 Brasil, 2008, Decreto Legislativo n. ${ }^{\circ}$ 186, de 9 de julho de 2008. Disponível em < http://www. planalto.gov.br/ccivil_03/CONGRESSO/DLG/DLG-186-2008.htm > (última consulta em outubro de $2021)$.

28 Brasil, 2009, Decreto n. ${ }^{\circ}$ 6949, de 25 de agosto de 2009. Disponível em < http://www.planalto. gov.br/ccivil_03/_ato2007-2010/2009/decreto/d6949.htm > (última consulta em outubro de 2021). 
psicossocial e movimentos sociais; direitos humanos e cidadania. As categorias presentes nesse relatório são usuários, pacientes, portadores de ou pessoas com transtorno mental, sofrimento mental e sofrimento psíquico.

O eixo Direitos Humanos e Cidadania (sus 2010) apresenta dentre os princípios gerais a proibição de tratamentos violentos e degradantes, as sanções aos serviços e políticas que excluam as pessoas portadoras de transtornos mentais, a revisão das interdições judiciais e a conquista dos direitos sociais. Como práticas degradantes e violentas, estão a lobotomia, a psicocirurgia, a eletroconvulsoterapia, as contenções físicas e químicas, as internações prolongadas e os maus-tratos. Como práticas a serem coibidas, estão o cárcere privado e as mortes não comunicadas em hospitais psiquiátricos, hospitais de custódia e tratamento, unidades prisionais e domicílios. A interdição civil é tratada no âmbito da prática judiciária e da assistência social. Por uma via, demanda-se a revisão das interdições com a suspensão das curatelas nos casos em que se comprovem negligências e abandono do curatelado pelo curador. Por outra, reforça-se a inexigibilidade da interdição para o acesso a benefícios sociais, especificamente o benefício da prestação continuada. A promoção dos direitos humanos se atrela à conquista dos direitos sociais elencados: moradia, transporte, lazer, esporte, educação, cultura, inclusão digital, trabalho e saúde.

A intersetorialidade, transformada em uma premissa, fomentou documentos importantes na interface da saúde e educação, moradia, assistência, trabalho e justiça. A Portaria Interministerial MS/MEC n. ${ }^{\circ} 6$ de 2010 instituiu o PET-Saúde/Saúde Mental, ${ }^{29}$ integrando ensino e serviço e objetivando a formação de profissionais de saúde antenados com as políticas de saúde mental. A Portaria n. ${ }^{\circ} 3088$ de 2011 , ao regulamentar a Rede de Atenção Psicossocial (RAP), ${ }^{30}$ estipula como componentes da RAP a atenção residencial de caráter transitório (Unidades de Acolhimento e Comunidades Terapêuticas), as estratégias de desinstitucionalização (Serviços Residenciais Terapêuticos e Programa de Volta para a Casa) e a reabilitação psicossocial (cooperativas sociais). As cooperativas destinadas às pessoas em desvantagem social, instituídas desde 1999, passaram a compor o Programa Nacional de Apoio ao Associativismo e ao Cooperativismo criado pelo Decreto n. 8163 de 2013. ${ }^{31}$ As pessoas

29 Brasil, 2010, Portaria Interministerial MS/MEC nº 06 de 17 de setembro de 2010. Disponível em < http://bvsms.saude.gov.br/bvs/saudelegis/sgtes/2010/poc0006_17_09_2010.html > (consultado em 24/06/2020).

30 Brasil, 201 l, Portaria GM/MS n. ${ }^{\circ} 3088$ de 23 de dezembro de 201 l. Disponível em < http://bvsms. saude.gov.br/bvs/saudelegis/gm/2011/prt3088_23_12_2011_rep.html > (última consulta em outubro de 2021).

31 Brasil, 2013, Decreto n. ${ }^{\circ} 8163$ de 20 de dezembro de 2013. Disponível em < http://www.planalto.gov.br/CCIVIL_03/_Ato201 1-2014/2013/Decreto/D8163.htm > (última consulta em outubro de $2021)$. 
portadoras de transtornos mentais em conflito com a lei foram contempladas com o serviço de avaliação e acompanhamento de medidas terapêuticas. Tal

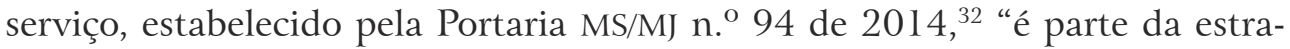
tégia para redirecionamento dos modelos de atenção à pessoa com transtorno mental em conflito com a Lei".

Em 2015, foi publicada a Lei n. ${ }^{\circ}$ 13.146, que instituiu o Estatuto da Pessoa com Deficiência. ${ }^{33}$ Essa lei merece atenção, pois alterou o Código Civil no tocante às pessoas consideradas absolutamente incapazes para atos da vida civil, à interdição e à curatela. Em seu artigo $84 .^{\circ}$, é apresentada a noção de "processo de decisão apoiada", responsável por retirar do Código Civil a denominação de pessoa absolutamente incapaz destinada àquelas que por enfermidade ou deficiência mental não tivessem o necessário discernimento para a prática de atos da vida civil, e por transformar a curatela em "medida protetiva extraordinária". A tomada de decisão apoiada é "o processo pelo qual a pessoa com deficiência elege pelo menos 2 (duas) pessoas idôneas, com as quais mantenha vínculos e que gozem de sua confiança, para prestar-lhe apoio na tomada de decisão sobre atos da vida civil, fornecendo-lhes os elementos e informações necessários para que possa exercer sua capacidade". A lei estipula que a curatela "não alcança o direito ao próprio corpo, à sexualidade, ao matrimônio, à privacidade, à educação, à saúde, ao trabalho e ao voto", afetando estritamente os direitos de natureza patrimonial e negocial.

\section{A DIMENSÃO CRIADORA DOS DOCUMENTOS: DO FAZER-SE CIDADÃO E DO FAZER-SE ESTADO}

Na literatura antropológica sobre documentos é frequente a ênfase na dimensão criadora dos mesmos, considerando os aspectos materiais que segundo Hull (2012) tendem a ser abordados com enfoque na estética, nos afetos e emoções, e nos signos. ${ }^{34}$ Para o autor, os estudos sobre os documentos exploram as capacidades de controle administrativo e de construção de sujeitos, objetos e socialidades. Dentre esses estudos, há uma inclinação para pesquisas etnográficas que entram em contato com os documentos em instâncias burocráticas nas quais é possível negociar o acesso ao arquivo, ao processo de construção, aos conteúdos e aos trâmites, evidenciando as relações entre os

32 Brasil, 2014, Portaria Interministerial MS/MJ n 94 de 14 de janeiro de 2014. Disponível em $<$ http://bvsms.saude.gov.br/bvs/saudelegis/gm/2014/prt0094_14_01_2014.html > (última consulta em outubro de 2021).

33 Brasil, 2015, Lei n. ${ }^{\circ} 13.146$ de 06 de julho de 2015. Disponível em < http://www.planalto.gov.br/ ccivil_03/_ato2015-2018/2015/lei/113146.htm > (última consulta em outubro de 2021).

34 Hull (2012: 255) especifica que: "If the aesthetics approach concentrates on form, and if attention to affect draws analysis to moments of encounter with documents, the problem for work oriented to signs is the way documents link to people, places, things, times, norms, and forms of sociality". 
técnicos, os demandantes, e o pesquisador que se coloca em cena. A inserção no cenário da produção, tramitação e arquivo dos documentos permite ao pesquisador o esforço de segui-los e analisá-los a contrapelo, tendo ao seu alcance um universo de relações micropolíticas que diz muito sobre as expectativas e os efeitos atribuídos a eles.

No Brasil é possível apontar como exemplos os trabalhos de Pinto (2014) sobre a produção dos documentos pela validação de papéis em um cartório; de Lowenkron e Ferreira (2014) com inquéritos referentes ao tráfico humano para exploração sexual e com processos administrativos concernentes ao desaparecimento de pessoas; de Vianna $(2002,2014)$ com os processos judiciais relativos à guarda de menores; e de Maricato (2015) a respeito da performatização da lei e da ordenação de sujeitos pela legislação garantidora de pensão aos atingidos pela hanseníase. Esses trabalhos foram realizados mediante a inserção dos pesquisadores em instâncias burocráticas, a fim de acessar os documentos e de acompanhar o que ocorria nos espaços nos quais a documentação figurava.

Desses trabalhos, apreende-se que os documentos travam uma comunicação e criam um circuito de pessoas, bens e palavras, pois se convertem na linguagem do Estado (Pinto 2014); são instrumentos garantidores da possibilidade de ação das pessoas por eles impactadas ou documentadas, isto é, as agências ganham forma e materialidades no e pelo papel (Lowenkron e Ferreira 2014); são construtores de realidades enquanto redefinidores de limites (individual, doméstico e estatal) e de formas de intervenção administrativa (Vianna 2002, 2014); e possuem centralidade na negociação e performatização do direito de determinados sujeitos, ordenando-os e também constituindo fatos (Maricato 2015).

Diferente dos trabalhos citados, o mapeamento apresentado nos tópicos anteriores não foi realizado presencialmente em nenhuma instância estatal, não foi exigida da pesquisadora nenhuma negociação para entrar nas instituições, acessar arquivos e conteúdos, ocorrendo exclusivamente pela entrada nos "espaços abertos" da internet. Hine, em entrevista a Campanella (2015: 168-169), afirma que a internet se tornou "uma infraestrutura tácita que favorece as plataformas sobre as quais falamos com mais frequência”, e que os governos estão cada vez mais dependentes dela para o uso de bancos de dados e realização de transações. A entrada nesses espaços abertos da burocracia brasileira é, ainda, assegurada pelas premissas da transparência e do acesso à informação. Segundo Teixeira e Lima (2010: 55), a transparência, um dos pilares que subjazem a concepção usual de governança, se liga "a existência de mecanismos pelos quais as tomadas de decisão dos governantes sejam passíveis de acesso público". Já o acesso à informação é visto por Nader (1972) como uma das vias de entrada nas organizações burocráticas, tendo em vista que as instituições públicas parecem não ser estruturadas para o acesso público. 
Contudo, semelhante às etnografias que se deram in loco, o trabalho nos sites e plataformas institucionais enfrenta algumas dificuldades, como os silêncios (vazios documentais e referenciais), as descontinuidades de materiais disponíveis nas páginas de governo devido às mudanças de gestão e de layouts, os arquivos escondidos e os documentos antigos não digitalizados acessíveis por demanda através dos canais de contato oficiais. Há também o esforço de encontrar índices de autenticidade e integralidade quando os documentos, que não estão presentes nas páginas oficiais do governo, são encontrados em outros endereços pela busca ampla dos navegadores. Defendo que a diferença no acesso aos documentos não exclui a possibilidade de encará-los por uma leitura a contrapelo e por via da dimensão criadora que os autores apontam com muita clareza. No caso de um mapeamento, é possível exercitar primeiramente o olhar para os documentos e depois projetar um olhar através deles, movimento inverso ao assinalado por Hull (2012) como o mais frequente na literatura antropológica.

A apresentação dos documentos enfatizou um conjunto de categorias e um conjunto de proposições de serviços e ações estatais que não se separam e que interferem um no outro de acordo com as mudanças efetivadas. As categorias e os serviços propostos ganham formas e intensidades diferentes dependendo do tipo de documento e das suas capacidades criadoras que se expressam em suas funções normativas, administrativas, participativas e associativas, que ora aparecem separadas, ora articuladas. Dessa maneira é importante vislumbrar que o que aparece em um relatório de conferência, em uma lei ou portaria sugere dimensões distintas, porque vem de caminhos diferentes e pode causar impactos diversos relativos a individualidades, socialidades e serviços. Por exemplo, a demanda pela extinção dos manicômios que aparece nos relatórios das conferências e alcança o Projeto de Lei n. ${ }^{\circ}$ 3657, é suavizada na Lei n. ${ }^{\circ} 10.216$, que entra em vigor deixando espaços para a internação, que por sua vez é contornada com a Portaria n. ${ }^{\circ} 3088$, que enfatiza os dispositivos comunitários não deixando espaços para os hospitais.

Os tipos de documentos são meios importantes para se verificar como se organizam e expõem expectativas e a maneira como elas são respondidas no decorrer dos anos. No que tange as respostas é possível apontar que as diretrizes das conferências e a assinatura de acordos internacionais são respeitadas e incorporadas nas leis e decretos. Já as leis e decretos são postos em prática pelas portarias, enquanto os resultados destas precisam ser buscados nos planos e ações governamentais. Olhar para os documentos é estar atento em como demandas de uma dimensão são contempladas em outras dimensões, alterando-as e reorganizando práticas. Nesse esforço, é importante se atentar para as relações de poder que se aderem aos documentos (Lowenkron e Ferreira 2014) e configuram parte das suas possibilidades de serem performados (Maricato 2015). No jugo das relações de poder estão inseridas tanto as 
categorias quanto os serviços, na medida em que nomear alguém é proporcionar a ele um conjunto de garantias e de possibilidades de ação, e estabelecer tipos de serviços é responder às demandas e também circunscrever pessoas. As categorias e os serviços redefinem limites individuais, domésticos e estatais e são vias de intervenção administrativa, seguindo a inspiração de Vianna (2002, 2014).

Os documentos brasileiros em vigor no ano de 1978 trazem em seus bojos três noções caras para a concepção de loucura e de quem é o louco: a incapacidade, a irresponsabilidade com o seu duplo que é a periculosidade presumida, e a generalidade. Essas noções podem aparecer articuladas e engendram práticas e serviços estatais condizentes com o que elas apregoam. A incapacidade, que anula os atos da vida civil praticados por alguém considerado louco, engendra o mecanismo da interdição e o instituto da curatela. Ao interditar e curatelar um indivíduo, a noção de incapacidade justificava a internação quando o curador julgava o indivíduo como inconveniente no convívio doméstico ou como carente de tratamento médico. A necessidade de instituições para o internamento se fundamentava tanto por questões de saúde quanto por critérios de conveniência de cada curador.

A irresponsabilidade, inseparável da presunção de periculosidade, proporciona a medida de segurança com modalidades que endossam a existência do manicômio judiciário e a constituição de outros espaços: as casas de custódia e tratamento, as colônias agrícolas, e os institutos de trabalho, de reeducação ou de ensino profissional. As modalidades de medidas de segurança criam níveis diversos de segregação correspondentes aos níveis de periculosidade presumida ligados aos atos cometidos.

Já a noção de generalidade aparece tanto nas categorias "psicopatas" e "loucos de todo o gênero" quanto nas diversas categorias de indivíduos sob os quais incidiam as mesmas práticas destinadas aos loucos, como os "toxicômanos", "alcoolistas", "ébrios habituais", "ociosos", "vadios" e "prostitutas". A generalidade permitiu (e de certa maneira impôs) que instituições de saúde e justiça abrigassem um conjunto de pessoas que se assemelhava muito à massa dos desatinados apontada por Foucault no período das grandes internações europeias do século XVII (Foucault 2007 [1972]). Em grande medida, a generalidade proporcionou que as estruturas asilares brasileiras, iniciadas no século XIX, tivessem uma longa vida no século XX e adentrassem o novo milênio.

Essas três noções subsidiaram um indivíduo menor, silenciado e violentado e ao mesmo tempo instituições que conjugavam princípios protetivos e ações punitivas. A violência que marca a relação entre as instituições e os indivíduos internados denota o imbricamento que as noções oficializadas nos documentos promovem de individualidades, socialidades e serviços. Os documentos vigentes em 1978 constroem a realidade dos indivíduos loucos, descortinando 
os limites que os circunscrevem, os lugares que podem ocupar e as intervenções administrativas que recaem sobre eles; mostram como eles estão submetidos a outros documentos (registros de interdição, laudos de cessação de periculosidade, atestados médicos, etc.) que definem as suas possibilidades de circulação, ações e interações.

Tal imbricamento permanece na luta pela cidadania do louco, tornando-se uma marca no seu reconhecimento enquanto um sujeito integral para o qual deveriam ser garantidos plenos direitos. Tenório (2002) afirma que a luta pela cidadania é a marca do processo brasileiro de reforma psiquiátrica, contudo é preciso acrescentar que esta noção ganha protagonismo imbricada com proposições de serviços. As críticas que inauguram a luta pela reforma psiquiátrica brasileira, ancoradas nos debates internacionais, na Lei n. ${ }^{\circ} 180$ da Itália e nas vivências cotidianas de profissionais envolvidos em instituições asilares, inicia o questionamento ora pelos serviços, justificando a busca pela cidadania, ora pela busca de cidadania, com a recategorização dos sujeitos, impondo a reestruturação dos serviços. Os documentos posteriores a 1978 ampliam o rol de categorias, fundamentam uma legislação específica para os pacientes psiquiátricos, esboçando direitos para os loucos e novos dispositivos de saúde.

Essas ações são frutos também da participação social que se organiza para se ter acesso e influência nos processos decisórios de construção de políticas. A participação social relativa às discussões sobre reforma psiquiátrica é um eco das mobilizações pela reforma sanitária e pela redemocratização do Brasil. Tanto Ciconello (2008) quanto Avritzer (2012) demonstram que as instâncias participativas aumentam e se pluralizam na década de 1980. Elas enfrentam o desafio de "abrir o Estado" partilhando do poder que tende a se concentrar no espaço da democracia representativa (Ciconello 2008) e "impõem mudanças na forma de fazer políticas do governo federal" (Avritzer 2012: 8).

As discussões sobre a desinstitucionalização dão o tom das diretrizes que compõem os relatórios finais das Conferências Nacionais de Saúde Mental, esferas tão importantes para as mudanças legislativas e experimentação de novos dispositivos. As conferências conjugam em suas diretrizes a necessidade de olhar o louco enquanto um indivíduo com direito à doença e tratamento digno e enquanto um cidadão com direitos plenos. O direito à doença (baseado no direito à subjetividade e de se vivenciar crises sem ser submetido a métodos coercitivos), expresso inicialmente na categoria "doente mental" e posteriormente nas categorias "pessoas com transtornos mentais" e "pessoas com sofrimento psíquico", elimina a equivalência entre indivíduo e patologia, defendendo que o indivíduo com transtorno mental seja considerado em sua "existência-sofrimento". O tratamento digno corresponde aos serviços extra -hospitalares e comunitários com equipes multiprofissionais.

Em todas as conferências aparecem diretrizes que objetivam a revisão, reformulação e extinção das noções de incapacidade, inimputabilidade e 
generalidade. ${ }^{35}$ Em suas premissas, a noção de incapacidade é atacada duramente porque além de tutelar o indivíduo, ela foi estendida de forma incorreta para os domínios laborativos, através da equivalência entre incapacidade para atos da vida civil e incapacidade para o trabalho. A equivalência entre os dois tipos de incapacidade foi operada por alguns agentes dos serviços de seguridade social que passaram a exigir a comprovação da interdição civil para a concessão de benefícios sociais destinados aos incapazes de se proverem e de trabalharem, gerando um exército de interditados. ${ }^{36}$ A noção de incapacidade para o trabalho, por outro lado, aproxima a concepção de transtorno mental da concepção de deficiência, na medida em que é na rubrica da deficiência que o indivíduo com transtorno mental alcança vários benefícios sociais e, mais recentemente, se livra da categoria de "absolutamente incapaz" que vigorou por mais de um século no Código Civil.

A noção de inimputabilidade é rechaçada por fomentar a manutenção das instituições asilares judiciárias e por promover prisões de longa duração para os indivíduos sob medida de segurança que necessitam de laudos de cessação de periculosidade para voltar ao convívio social. Não ter pena, para muitos indivíduos, se transforma em um número de anos de reclusão maior do que a pena máxima existente para os apenados. Por sua vez, a noção de generalidade vem sendo enfraquecida com a instituição de uma rede de atenção psicossocial que conta com dispositivos de atenção básica e dispositivos específicos para as pessoas com transtornos mentais e necessidades decorrentes do uso de álcool e outras drogas. O combate à noção de generalidade é inerente ao combate às estruturas asilares; a pluralização de serviços e dispositivos coloca em cheque instituições totais para indivíduos classificados com conceitos amplos, como, por exemplo, "loucos de todo o gênero".

As legislações que alcançam as "pessoas portadoras de transtorno mental" e a reorientação da assistência se basearam nos direitos dos "usuários" pactuados nas conferências: direitos específicos no âmbito da assistência em saúde - direito à informação, comunicação e integridade física (proibição de internação prolongada, medicação excessiva, procedimentos invasivos, psicocirurgias, esterilização, etc.) - e direitos sociais plenos - participação social, saúde, educação, habitação, trabalho, renda, justiça, transporte, lazer, cultura, etc. A garantia dos direitos plenos dos indivíduos requer serviços e práticas de diversos setores estatais, o que confere uma grande importância à ideia de

35 Em 1984, a ideia de desinstitucionalização influenciou a substituição da categoria "irresponsáveis" pela de "inimputáveis" no Código Penal, mantendo, no entanto, a irresponsabilidade e a periculosidade subsumidas na nova noção.

36 Em 2005, a Câmara dos Deputados realizou a audiência pública sobre a banalização da interdição judicial no Brasil, apontando que as equivalências de incapacidades se configuravam como um atentado à democracia e aos direitos humanos (Câmara dos Deputados 2005). 
intersetorialidade. Intersetorialidade é o resultado de inúmeros esforços para se considerar o indivíduo "louco" enquanto sujeito integral, um cidadão pleno, demandante de ações (e não menos fruto de interpretações e intérpretes) de diversos profissionais e instâncias.

Considerando que, desde o ano de 1978, as questões ligadas à loucura mobilizam instâncias estatais para além das atreladas à saúde e que, de 2010 em diante, a Politica de Saúde Mental se propõe intersetorial, proponho que as categorias e os serviços dispostos nos documentos nos permitem uma leitura do processo do fazer-se Estado que o campo da saúde mental ajuda a engendrar. Lima e Castro (2015) apontam que os estudos antropológicos acerca das políticas públicas não devem se encerrar como um fim em si mesmo, pois precisam ser vistos como vias de acesso ao Estado e às lutas sociais, ressaltando que a configuração do Estado é maleável, plástica e escorregadia. É necessário frisar que a cada categoria oficializada ou serviço proposto, alteram-se práticas e dinâmicas que conformam o Estado. Dessa maneira, a governança, enxergada pela ótica "das tecnologias de governo que criam segmentos sociais por dispositivos que se estatizam ao longo do tempo" (Teixeira e Lima 2010: 55-56) inventa também continuamente o Estado.

\section{CONSIDERAÇÕES FINAIS}

O mapeamento apresentado é um exercício de mostrar a ligação entre a oficialização de categorias e as proposições de serviços e, consequentemente, a continuidade entre os processos de formação da cidadania e conformação estatal. Os documentos brasileiros revelam que a demanda por mudanças, pluralização e eliminação de categorias se articula com as exigências de ampliação, criação e extinção de serviços. A ampliação presente tanto na esfera das categorias quanto na esfera dos serviços decorre do processo de formação de cidadania para o louco, que combina direitos específicos para usuários de dispositivos de saúde e direitos sociais plenos que demonstram que as questões sobre loucura transcendem o campo da saúde. A proposição de serviços altera as práticas e a conformação do Estado, na medida em que eles se configuram como o Estado em operação.

A dimensão criadora dos documentos sinaliza que estes são construtores das realidades não só dos indivíduos categorizados, mas também do processo de fazer-se Estado que tem nos serviços uma face de alcance imediato. Os documentos colocados em sequência permitem identificar que a criação de segmentos sociais pelas tecnologias de governo envolve simultaneamente a redefinição de limites individuais, domésticos, profissionais, institucionais e estatais; limites que sofrem alterações constantes com as respostas e adequações de cada lado. Assim, não se constrói somente a cidadania para o louco, se constrói serviços, se habilita e interpela profissionais, se enfatiza o processo do fazer-se Estado a partir de categorias específicas. 


\section{BIBLIOGRAFIA}

AmARANTE, Paulo, 2009, Loucos pela Vida: A Trajetória da Reforma Psiquiátrica no Brasil. Rio de Janeiro: Editora Fiocruz.

AVRITZER, Leonardo, 2012, Conferências Nacionais: Ampliando e Redefinindo os Padrões de Participação Social no Brasil - texto para discussão 1739. Rio de Janeiro: IPEA.

BRASIL, 2003, Código Civil: Quadro Comparativo 1916/2002. Brasília: Senado Federal, Subsecretaria de Edições Técnicas.

BRASIL, 2007 [1988], Constituição de 1988. Constituição da República Federativa do Brasil. Brasília: Supremo Tribunal Federal.

CÂMARA dOS DePUTADOS, 2005, Audiência Pública: Banalização da Interdição Judicial no Brasil. Brasília: Relatórios da Câmara dos Deputados.

CAMPANELLA, Bruno, 2015, "Por uma etnografia para a internet: transformações e novos desafios”, MATRIZes, 9 (2): 167-173.

CHAVES, Lilian, 2016, Modelos de Assistência e Identidades Engendradas: Notas sobre Política e Saúde Mental no Brasil, Anais da 30. ${ }^{a}$ Reunião Brasileira de Antropologia. João Pessoa: $\mathrm{ABA}$

CICONELlO, Alexandre, 2008, "A participação social como processo de consolidação da democracia no Brasil", in Duncan Green (org.), From Poverty to Power: How Active Citizens and Effective States Can Change the World. Rugby: Oxfam International.

COSTA, Jurandir, 2007, História da Psiquiatria no Brasil: Um Corte Ideológico. Rio de Janeiro: Garamond.

DElGADO, Paulo, 1989, Projeto de Lei $n .^{\circ}$ 3657/89. Brasília: Câmara dos Deputados.

DElGADO, Pedro, 1992, As Razões da Tutela: Psiquiatria, Justiça e Cidadania do Louco no Brasil. Rio de Janeiro: Te Corá.

FOUCAUlT, Michel, 2007 [1972], História da Loucura. São Paulo: Perspectiva.

FOUCAUlT, Michel, 2008 [1979], Microfísica do Poder. São Paulo: Graal.

HULL, Matthew, 2012, "Documents and bureaucracy", Annual Review of Anthropology, 41: 251-267.

LIMA, Antônio Carlos, e João Paulo CASTRO, 2015, "Notas para uma abordagem antropológica da(s) política(s) pública(s)”, Revista Anthropológicas, 26 (2): 17-54.

LOWENKRON, Laura, e Letícia FERREIRA, 2014, "Anthropological perspectives on documents: Ethnographic dialogues on the trail of police papers", Vibrant (Brasília, ABA) 11 (2): 76-112.

MARICATO, Glaucia, 2015, “Ordenando sujeitos. Histórias performadas da Lei 1 1.520/2007”, in Claudia Fonseca e Helena Machado (orgs.), Ciência, Identificação e Tecnologias de Governo. Porto Alegre: UfRGS/CEGOV, 96-120.

MEDEIROS, Tácito, 1993, "Uma história da psiquiatria no Brasil”, in Jane Russo e João Ferreira Filho (orgs.), Duzentos Anos de Psiquiatria. Rio de Janeiro: Relume Dumará, Ed. UFRJ, 73-83.

MINISTÉRIO DA SAÚDE, 1988, I Conferência Nacional de Saúde Mental, 25 a 28 de Junho de 1987: relatório final. Brasília: Centro de Documentação do Ministério da Saúde, 1-43.

MINISTÉRIO DA SAÚDE, 1992, Relatório Final da II Conferência Nacional de Saúde Mental. Brasília: Ministério da Saúde, 1-63.

NADER, Laura, 1972, "Up the anthropologists: perspectives from studying up", in Dell Hymes (org.), Reiventing Atnhropology. Nova Iorque: Pantheon Books, 284-310. 
PEIRANO, Mariza, 2006(a), A Teoria Vivida e Outros Ensaios de Antropologia. Rio de Janeiro: Jorge Zahar Editor.

PEIRANO, Mariza, 2006(b), "De que serve um documento?”, in Moacir Palmeira e César Barreira (orgs.), Política no Brasil: Visão de Antropólogos. Rio de Janeiro: Relume Dumará, 25-49.

PINTO, Danilo, 2014, "Um antropólogo no cartório: o circuito dos documentos", Campos, 15 (1): 37-56.

RUSSO, Jane, 1993, "Psiquiatria, manicômio e cidadania no Brasil”, in Jane Russo e João Ferreira Filho (orgs.), Duzentos Anos de Psiquiatria. Rio de Janeiro: Relume Dumará, Ed. UFRJ, 7-10.

SUS - SISTEMA ÚNICO DE SAÚDE, 2002, Relatório Final da III Conferência Nacional de Saúde Mental. Brasília, 11 a 15 de dezembro de 2001. Brasília: Conselho Nacional de Saúde/ Ministério da Saúde.

SUS - SISTEMA ÚNICO DE SAÚDE, 2010, Relatório final da IV Conferência Nacional de Saúde Mental - Intersetorial. Brasília, 27 de Junho a 1 de Julho de 2010. Brasília: Conselho Nacional de Saúde/Ministério da Saúde.

TEIXEIRA, Carla, e Antônio Carlos LIMA, 2010, "A antropologia da administração e da governança no Brasil: área temática ou ponto de dispersão?”, in Luiz Fernando Duarte e Carlos Benedito Martins (orgs.), Horizontes das Ciências Sociais no Brasil: Antropologia. São Paulo: ANPOCS, 51-95.

TENÓRIO, Fernando, 2002, "A reforma psiquiátrica brasileira, da década de 1980 aos dias atuais: história e conceitos", História, Ciências, Saúde - Manguinhos, 9 (1): 25-59.

VENÂNCIO, Ana Teresa, 2005, "As faces de Juliano Moreira: luzes e sombras sobre seu acervo pessoal e suas publicações”, Revista Estudos Históricos, 2 (36): 59-73.

VIANNA, Adriana, 2002, "Quem deve guardar as crianças? Dimensões tutelares da gestão contemporânea da infância”, in Antônio Souza Lima (org.), Gestar e Gerir: Estudos para Uma Antropologia da Administração Pública no Brasil. Rio de Janeiro: Relume Dumará, 271-312.

VIANNA, Adriana, 2014, "Etnografando documentos: uma antropóloga em meio a processos judiciais", in Sérgio Castilho, Antônio Souza Lima e Carla Teixeira (orgs.), Antropologia das Práticas de Poder: Reflexões Etnográficas entre Burocratas, Elites e Corporações. Rio de Janeiro: Contra Capa, 43-70.

ZEITLYN, David, 2012, "Anthropology in and of the archives: possible futures and contingent pasts. Archives as anthropological surrogates", Annual Review of Anthropology, 41: 461-480. 